\title{
Barium-selective Chromoionophoric Properties of Nitro Derivative of Calix[4|arene-crown Ethers
}

\author{
Ju Hee Kim and Suk-Kỵu Chang \\ Depatment of ('hemistry, ('hung-Ang Finersity, Seoul 156-756, Korea \\ Received IArch H1, 2003
}

Key Words : Cali\[4]arene; Nitrophenol, Chromerionophore, Bariun-welectivity

There has been much interest for the development of efficient and selective chromogenic and fluorogenic ionophore systems. ' Many compounds are based on the wellknown molecular framework of crown ethers. calixarenes, and other EDTA type efficient chelating compounds.' Among them the ionophores derived from the calix[+]arenes are particularly attractive for their efficient ionophoric properties toward some of important guest ions. ${ }^{3}$ Particularly, the calix[4]arene-crown ethers are known to have unique binding properties toward alkali, alkaline earth metal ions, and organic amines. ${ }^{4}$ Many of spectroscopic sensing materials are developed by conjugating molecular framework of calix[4]arene-crown ethers with suitable signaling functions of azophenols. thiazoles. and aminoquinones." Quite unexpectedly, however. the ionophoric properties of simple nitro derivative of calix[+]arene-crown ethers were not reported. except for the closely related structure having ester-ether functions in crown moiety:" in spite of their synthetically easy availability and efficient ionophoric properties. In this paper. we report the synthesis of dinitro derivative of calix[4]arene-crown ethers and their ionophoric properties toward representative alkali and alkaline earth metal ions aiming for the development of efficient and selective chromogenic sensing material for the barium ions.

Dinitro derivatives $\mathbf{2} \mathbf{a}$ and $\mathbf{2} \mathbf{b}$ were prepared by the selective nitration of calix[4]arene-crown-5 ether $^{\circ}$ 1a and calix [4]arene-crown-6 ether 1 b with $\mathrm{HNO}_{3}\left(\mathrm{HOAc}_{2} / \mathrm{CH}_{2} \mathrm{Cl}_{2}\right)$ on unsubstituted phenol groups in good yield (88-92\%) (Scheme 1). The resonances for the bridging methylene protons are observed at $\delta+.46$ and 3.49 indicating that the nitro derivatives adopt a cone conformation in solution. Phenolic $\mathrm{OH}$ resonances were observed at relatively down field of $\delta 8.81-8.97$. as expected from the presence of a nitro group on the phenol ring. In their IR spectnum. characteristic bands of a nitro group were observed at 1512 and $1337 \mathrm{~cm}^{-1}$.

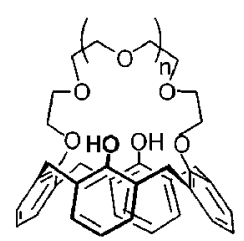

1
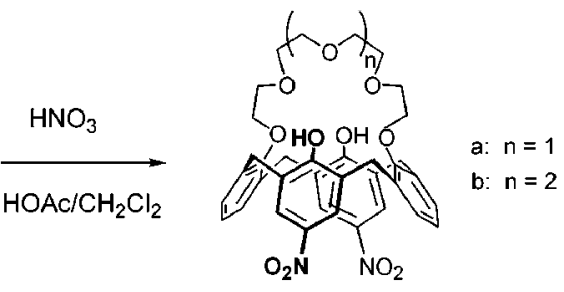

2
Scheme 1
The structure of calix|+ Jarene crown- -5 ether is known to have high selectivity toward large alkaline eartl metal ions of $\mathrm{Ba}^{21}$. We have utilized the nitrophenol groups ${ }^{|"|}$ for the signaling unit which can be prepared easily by selective nitration of phenols and can also be used as electroactive functions."

The chromogenic ionophore properties of 2 were inestigated by examining the UV-Vis absorption behaviors of the host in common organic solvents. Among the solvent system surveyed. $\mathrm{CH}_{3} \mathrm{CN}-\mathrm{MeOH}$ mixture was found to be most efficient and selective for the development of chromogenic responses. In $\mathrm{CH}_{3} \mathrm{CN}-\mathrm{MeOH}$ nixture $\left([2 \mathbf{a}]=1 \times 10^{-5} \mathrm{M}\right.$. $\mathrm{CH}_{3} \mathrm{CN}: \mathrm{MeOH}=1: 9$. v/v) the crown-5 ionophore 2a showed a broad absorption band around $326 \mathrm{~lm}$ which is a characteristic of the $p$-nitrophenol moiety (Figure 1). Addition of 100 equiv of metal ions in perchlorate resulted in the appearance of a new band due to the formation of nitrophenoxide in the ionophore around $+41 \mathrm{~nm}$. The color of the solution tumed from colorless to yellow: The $\mathrm{Ba}^{2}$. ions showed most pronounced response that is in good agreement with previous reported selectivity and the induced absorbance intensity at $+41 \mathrm{~mm}$ decreases in the order of $\mathrm{Ba}^{2} \gg \mathrm{Ca}^{21}>\mathrm{Mg}^{21} \approx \mathrm{K} \approx \mathrm{Na}^{\prime} \approx \mathrm{Li}$. The increase in the absorption band at $+4 \mathrm{lmm}$ is around 300 -fold with $\mathrm{Ba}^{2}$. ions. With $\mathrm{Ca}^{21}$ ion, the increase in the absorption band is less significant (around 70-fold) and somewhat blue shift

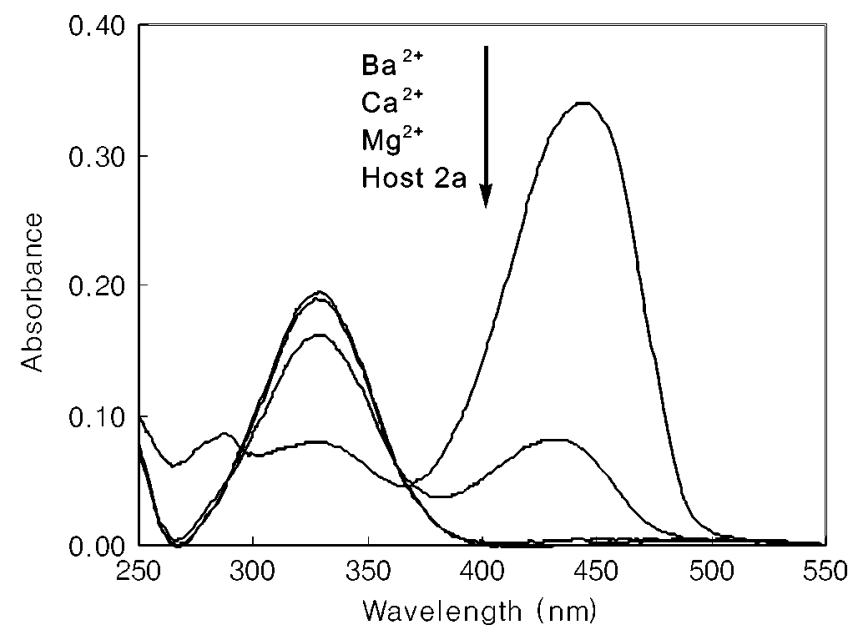

Figure 1. Absotption spectra of $\mathbf{2 a}$ in the presence of metal ions. $[2 \mathrm{a}]=10 \times 10^{-5} \mathrm{M},\left[\mathrm{M}^{21}\right]=1.0 \times 10^{-3} \mathrm{M}$ in $\mathrm{CH}_{3} \mathrm{CN}-\mathrm{MoOH}(1: 9$ iv). 
$\left(\lambda_{\text {toax }}=430 \mathrm{~nm}\right)$ was also observed when compared with $\mathrm{Ba}^{2}$ ions. Other metal ions $\left(\mathrm{Li}^{\prime} . \mathrm{Na}^{\prime} . \mathrm{K}\right.$, and $\left.\mathrm{Mg}^{2}\right)$ induced no significant clanges in the spectral behaviors of $\mathbf{2 a}$.

The chromogenic behavior of homologous calix[+]arenecrown- 6 ether $\mathbf{2 b}$ was also in estigated. Under the same conditions. the ionophore itself showed somewhat residual absorbance at $430 \mathrm{~nm}$ without interaction with any metal ion in addition to the strong absorption band at $326 \mathrm{~mm}$. Upon addition of $\mathrm{Ba}^{2}$ ions. the absorption band at $448 \mathrm{~nm}$ increased markedly and the color of the solution also turned into yellow one exhibiting almost identical spectral changes of $2 \mathrm{a}-\mathrm{Ba}^{21}$ system. On the other hand, with $\mathrm{Ca}^{2}$ ions a strong absorption band at $430 \mathrm{~nm}$ was observed. which is about $77 \%$ of the absorption intensity induced by the interaction with $\mathrm{Ba}^{21}$ ions. The enlanced response toward the $\mathrm{Ca}^{2}$ ions significantly reduces the $\mathrm{Ba}^{2}$ selectivity of the crown-6 ether $\mathbf{2 b}$.

To have a further insight into the chromogenic behavior of the ionophore 2a. the absorption profile as a function of metal ion concentration was obtained (Figure 2). Ionophore 2a exlubited a gradual increase in absorption intensity at the $\lambda_{\text {max }}$ of $4+1 \mathrm{~nm}$ upon addition of incremental barium ions up to 3 equiv then leveled off. From the plot of absorbance versus metal ion concentration for $2 \mathrm{a}^{-}-\mathrm{Ba}^{2}$ system, the detection limit $^{12}$ of $2 \times 10^{-6} \mathrm{M}$ was found which is suitable for the analysis of barium ions in the nicromolar concentration range. From the plot of the absorbance changes of $2 a^{-}-\mathrm{Ba}^{2}$ system the association constant was determined by nonlinear curve fitting procedure and found to be $2.4 \times 10^{i} \mathrm{M}^{-1}$ in this solvent system of $\mathrm{CH}_{3} \mathrm{CN}-\mathrm{MeOH}$ $(1: 9 . \mathrm{v} / \mathrm{)})$. For $\mathrm{Ca}^{21}$ ions, somewhat smaller value of $1.1 \times 10^{+} \mathrm{M}^{-1}$ was obtained. Other metal ions induced too small changes in absorption spectra to estimate reliable association constants.

The selective response of nitro derivative toward barium ions was further evidenced by the experiments performed in the presence of background metal ions (100 equiv of $\mathrm{Li}^{\prime}$. $\mathrm{Na}^{\prime} . \mathrm{K}^{\prime}$. $\mathrm{Mg}^{2}$. and $\left.\mathrm{Ca}^{2}\right)$. Ionophore 2a exhibited very

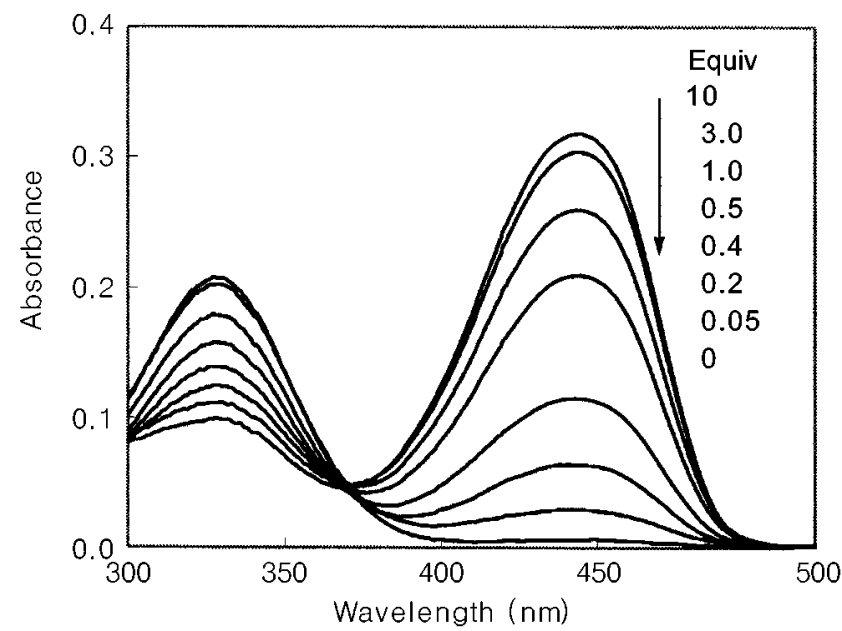

Figure 2. Changes in absorption spectra as a function of $\left[\mathrm{Ba}^{2-}\right]$. $[2 \mathrm{a}]=1 \times 10^{-4} \mathrm{M}$ il $\mathrm{CH}_{3} \mathrm{CN}-\mathrm{MeOH}(1: 9, \mathrm{v} / \mathrm{v})$. similar $\mathrm{Ba}^{2}$-selective response profile as compared with the results obtained in the absence of any background metal ions except for somewhat increased residual absorbance due to the presence of large quantity of calcium ions. The $\mathrm{Ba}^{2}$. selectivity of the ionophore can be utilized as a new sensor material for the deternination of barium ions ${ }^{1.3}$ as well as the sulfate ions in mineral waters. ${ }^{14}$

ln conclusion. simple nitro derivative of calix[4]arenecrown-5 ether showed a selective molecular recognition behavior toward barium ions over other alkali and alkaline earth metal ions. The prepared nitro derivatives can be used as a new and selective chromogenic probe for the sensing of barium ions in chemical systems.

\section{Experimental Section}

General. Calix[+]arene, tetra(ethy lene glycol) di-p-tosylate. and penta (ethylene glycol) di-p-tosylate were purchased from Aldrich and used without further purification. NMR spectra were obtained with a Varian Gemini 2000 NMR spectrometer $(300 \mathrm{MHz})$. UV-Vis absorption spectra were recorded with a Jasco V-550 UV spectrometer. FAB-MS spectra were measured with a Micromass Autospec mass spectrometer. Calix[4]arene-crown-5 ether and calix[4]arenecrown- 6 ether were prepared by following the reported procedure. $^{*}$

Preparation of nitro derivatives 2 . Calix-crown ether 1a (500 mg. $0.835 \mathrm{~mm}$ mole) was dissolved in dichloromethane (10 $\mathrm{mL}$ ) and subsequently added $\mathrm{HNO}_{3}(0.4 \mathrm{~mL})$ and $\mathrm{HOAc}$ $(0.5 \mathrm{~mL})$ solution. The solution was stirred at it for $30 \mathrm{~min}$ until the reaction was completed (monitored by TLC). The reaction mixture was washed with water twice and the organic layer was evaporated under reduced pressure. The crude residue was purified by crystallization from $\mathrm{CH}_{2} \mathrm{Cl}_{2}$ $\mathrm{MeOH}$. Nitro-crown-5 ether 2a. Yield: 92\%: 'H NMR $\left(\mathrm{CDCl}_{3}\right) \delta 8.97$ (s. $\left.2 \mathrm{H} . \mathrm{ArOH}\right) .8 .06$ (s. $\left.4 \mathrm{H} . \mathrm{NO}_{2}-\mathrm{ArH}\right) .6 .95$ (d. $4 \mathrm{H} . J=7.5 \mathrm{~Hz}, \mathrm{ArH}$ ). 6.83 (t. $2 \mathrm{H} . J=7.6 \mathrm{~Hz}, \mathrm{ArH}$ ), 4.46 and 3.49 (d. $4 \mathrm{H}$ each $J=13.3 \mathrm{~Hz}, \mathrm{ArCH}_{2} \mathrm{Ar}$ ). $4.14,4.10$. 3.89 and 3.82 (br m, $4 \mathrm{H}$ each. $\mathrm{OCH}_{2}$ ); FAB-MS (m-NBA) calcd for $[\mathrm{M}+\mathrm{H}] \mathrm{C}_{36} \mathrm{H}_{3}-\mathrm{N}_{2} \mathrm{O}_{11}$ 673.2, found 673.16. Nitrocrown-6 ether 2b was prepared similarly: Yield: $88 \%:{ }^{~} \mathrm{H}$ $\mathrm{NMR}\left(\mathrm{CDCl}_{3}\right) \delta 8.81$ (s. $\left.2 \mathrm{H} . \mathrm{ArOH}\right) .8 .06$ (s. $4 \mathrm{H}$. $\mathrm{NO}_{2}-$ ArH) .6 .94 (d. $4 \mathrm{H} . J=7.5 \mathrm{~Hz}$. ArH). 6.81 (t. $2 \mathrm{H} . J=7.6 \mathrm{~Hz}$. ArH). 4.46 and 3.49 (d. $4 \mathrm{H}$ each. $J=13.2 \mathrm{~Hz}, \mathrm{ArCH}_{2} \mathrm{Ar}$ ), 4.20. 4.00. 3.88. and 3.81 (br m. $+\mathrm{H}$ each. $\mathrm{OCH}_{2}$ ). 3.65 (s. $\left.+\mathrm{H}, \mathrm{OCH}_{2}\right)$ : FAB-MS ( $m$-NBA) calcd for $[\mathrm{M}+\mathrm{H}] \mathrm{C}_{18} \mathrm{H}_{41} \mathrm{~N}_{2} \mathrm{O}_{12}$ 717.3, found 717.3 .

UV measurements. Stock solutions of ionophore $2(1 \times$ $10^{-4} \mathrm{M}$. in $\left.\mathrm{CH}_{3} \mathrm{CN}\right)$ and metal perchlorate $\left(\mathrm{I} \times 10^{-2} \mathrm{M}\right.$. in $\mathrm{MeOH}$ ) were prepared. The metal solution was diluted 10 and 100 times to give $\mathrm{I} \times 10^{-3} \mathrm{M}$ and $1 \times 10^{-4} \mathrm{M}$ solutions. Aliquots of metal solution was added to the ionophore solution and the final concentration and composition of the solution were adjusted to the desired value by adding extra $\mathrm{MeOH}$.

Acknowledgements: This work was supported by a fund 
from Chung-Ang University (2002) and gratefully acknowledged.

\section{References}

1. Hayshita. I:: Tuhagi. M. In Comprehensive Supramolecular (hemstm: Gokel. G. W. Ed.: l'ergumon: Oslord. 1996: Vol. 1. pP $635-660$.

2. Chemosensors of ton and Wolecwle Rectognition: Desvergne, J. P.; Cramik, A. W.. Eds.: Kluwer: Dordrecht, 1997. (b) Flnon'scent Chemosensors for lon and Holecule Rucognition C7arnik, $\Lambda$. W. Ed: American Chemical Soxiely: Washinglon. DC: 1993.

3. C'ahromenes 2001: Aslari. L.: Böhmer. V.: Harrowlield. J.: Vicens. J.. Eds.: Kluwer: Dordrecht. 2001.

4. (a) Kubo, Y:: Obara. S.: Tokita. S. Chom. Commm. 1999. 2.399 (b) Kubo, Y:: Maruvama. S: Olhara. N:: Nakamura, M.: Tokita. S. J. Chem. Soc Chem. Common. 1995. 1727.

5. (a) King. A. M.: Moore. C. l':. Sandanavake. K. R. A.: Sutherland.
1. O. J. Chem Soc. (hem Commm, 1992. 582. (b) Kim. Y. Н.: Cha. N. R.: Chang. S.-K. Tetrohedron Lett, 2002. 43.3883,

6. Mahajan. R. K.: Kumar. M.: Sharma. V.: Katur. I. Talanta 2002. 58, 445. (b) 7heng. Q.-Y.: Chen, C.-F.: I luang. 7.-T. Fetrathedron $1997,53.10345$

7. Chen, X.; Ji. M.: Fisher, D. R.: Wai. C. M. Synleff 1999 , 1784 .

8. Guillon. J.: Leger. J.-M.: Somet. P?.: Jarry. C.: Robba. M. J. Org. (hem. 2000. 65. 8283 .

9. Cacciapaglia. R.; Mandolini. I. Chm. Soc, Rev 1993. 22, 221 .

10. McKerver: M. A.: Mulhalland. D. I. J. Chm Soc. Chom. Commm 1977. 438.

11. Delgado. M.: Echegoven. L.: Gatto. V. I.: Gustonski. D. A.: Gokel. G. W. J. in Chem Soc 1986. 108. 4135.

12. Shortreed. M.: Kopelman. R.: Kuhn. M.: Họland. B. Anat. ('hom. 1996.68 .1414

13. Salch, M. B. Finstemins J, Anal Chem. 2000, 367. 530

14. Bouklouze, $\Lambda$. A.: Vire, J.-C.: Cool. V. Anal. Chim. Acta 1993. 273.153. 